\title{
Uma revisão histórica do planejamento do setor elétrico brasileiro
}

Sonia Seger Pereira Mercedes

Julieta A. P. Rico Liliana de Ysasa Pozzo 


\section{RESUMO}

O setor elétrico brasileiro vem sofrendo sucessivas revisões e reformas nos últimos 30 anos. Ainda que, no discurso, essas reformas sempre visem ao melhor e mais universal atendimento às necessidades da sociedade, na prática, esse resultado nem sempre esteve em primeiro plano. E mesmo sendo um critério prioritário de planejamento, a garantia da segurança do abastecimento foi alterada ao longo dessa sucessão de mudanças no modelo setorial de gestão. Atualmente, em um cenário de planejamento da expansão e da operação de alta complexidade, esse critério ostenta o caráter de particularidade brasileira frente ao cenário internacional, pairando sobre a sociedade uma persistente ameaça de "crise" do serviço de energia elétrica. Nesse contexto, este artigo elabora uma reconstituição histórica do processo de planejamento do setor elétrico em termos da importância da segurança do abastecimento.

Palavras-chave: planejamento energético; segurança do abastecimento; reestruturação setorial; histórico.

\section{ABSTRACT}

The Brazilian electrical power sector has been going through successive reviews and reforms in the past 30 years. Although those reforms have, in theory, always been meant to better and more extensively meet the needs of society, in practice that result has not always been given top billing. Even though guarantee of security of supply has been given a top priority rating, it has been changed throughout that string of changes in the management model for the sector. Currently, in a scenario of expansion planning and operation of high complexity, that criterion features the character of the Brazilian singularity in face of the international scenario, and a persistent threat of a "crisis" in the provision of electric energy hovers over society. With that as a background, this article draws a historical picture of the planning process of the electrical power sector as it concerns to the importance ascribed to security of supply.

Keywords: energy planning; security of supply; restructuring of the sector; history. 


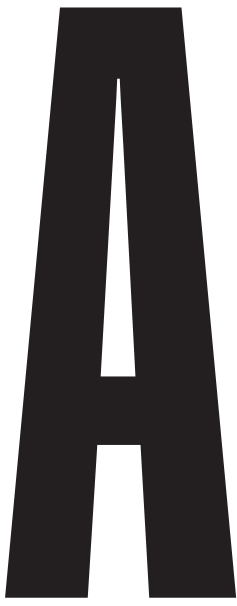

atividade de planejamento no setor elétrico foi construída e sofreu várias mudanças ao longo da existência dessa indústria a partir de uma origem em que o planejar não era uma preocupação prioritária, ou mesmo, existente. A substituição do modelo privado e descentralizado por uma crescente participação estatal e centralização da gestão - decorrente da permanente defasagem existente entre as demandas que se ampliavam e diversificavam e a insuficiente oferta de eletricidade - introduziu a necessidade e as visões de planejamento, que também se sucederam ao longo das várias reformas setoriais ocorridas. A Tabela 1 resume as principais características do setor elétrico brasileiro em cada período vinculado a um modelo institucional vigente. A Figura 1 mostra a atual estrutura institucional da indústria de energia no Brasil.

O foco do processo de planejamento em cada uma das etapas de institucionalização e reforma do setor elétrico pode ser resumido como:

- Início: obtenção de economias de escala; superação contínua das barreiras tecnológicas e de conhecimento.

- Período estatal: planejamento energético normativo (GCPS - Grupo Coordenador do Planejamento do Sistema); economias de escala e de escopo; regularidade tecnológica - grandes usinas hidrelétricas (até os anos 1970); capacidade instalada de geração e de transmissão crescentes, para atender a uma demanda crescente; após os anos 1970 promoção de diversidade tecnológica e de fontes.

- Período mercantil - FHC: planejamento energético indicativo (CCPE - Comitê Coordenador do Planejamento da Expansão); o incremento da participação do gás natural na matriz energética é a principal meta em termos de desenvolvimento de recursos.

- Período mercantil - Lula e Rousseff: planejamento integrado e estratégico (empresa de pesquisa energética); participação pública (consultas e audiências); fontes renováveis são consideradas "complementares", ao invés de "alternativas".

Este trabalho foi apoiado pela Capes, Programa Nacional de Pós-Doutorado - PNPD, projeto n. 59.528-2010.

SONIA SEGER PEREIRA MERCEDES é membro do corpo técnico do Instituto de Energia e Ambiente (IEE) da USP, colaboradora do grupo de pesquisa Resíduos Sólidos Urbanos e Impactos Socioambientais da FAU-USP e pesquisadora do IEE-USP.

JULIETA A. P. RICO é pesquisadora na área de economia dos recursos naturais no tema Renda de Energia Elétrica, dentro do Programa Nacional de Pós-Doutorado (PNPD) da Capes.

LILIANA DE YSASA POZZO é membro do corpo técnico do Instituto de Energia e Ambiente (IEE) da USP, na Divisão Científica de Planejamento, Análise e Desenvolvimento Energético, e atua no Serviço Técnico de Planejamento, Análise Econômica e Social e Desenvolvimento de Recursos Energéticos (Paesdre). 


\section{TABELA 1}

\section{FASES DA ESTRUTURAÇÃO DO SETOR ELÉTRICO BRASILEIRO}

\begin{tabular}{|c|c|c|c|c|c|}
\hline Período & 1880 & 1930 & 1960 & 1990 & 2003 \\
\hline $\begin{array}{c}\text { Propriedade } \\
\text { de ativos }\end{array}$ & Privada & Privada & Estatal & Privada & Semiprivada \\
\hline $\begin{array}{l}\text { Principal } \\
\text { objetivo }\end{array}$ & $\begin{array}{l}\text { Implantação e } \\
\text { consolidação }\end{array}$ & Institucionalização & Crescimento & $\begin{array}{l}\text { Introdução de } \\
\text { competição }\end{array}$ & $\begin{array}{c}\text { Universalização } \\
\text { do acesso }\end{array}$ \\
\hline Economia & Agroexportadora & $\begin{array}{l}\text { Industrialização } \\
\text { (substituição de } \\
\text { importações) }\end{array}$ & $\begin{array}{c}\text { Grandes } \\
\text { companhias }\end{array}$ & $\begin{array}{c}\text { Desestatização e } \\
\text { neoliberalismo }\end{array}$ & Desenvolvimentismo \\
\hline $\begin{array}{l}\text { Processo de } \\
\text { regulação } \\
\text { tarifária }\end{array}$ & $\begin{array}{l}\text { Contratos } \\
\text { bilaterais }\end{array}$ & Cláusula Ouro & Custo do serviço & $\begin{array}{l}\text { Preço-teto } \\
\text { incentivado }\end{array}$ & $\begin{array}{l}\text { Preço-teto } \\
\text { incentivado }\end{array}$ \\
\hline $\begin{array}{c}\text { Maior } \\
\text { demanda }\end{array}$ & $\begin{array}{l}\text { Iluminação } \\
\text { pública e } \\
\text { transporte }\end{array}$ & $\begin{array}{c}\text { Urbanização e } \\
\text { industrialização }\end{array}$ & $\begin{array}{l}\text { Indústria e } \\
\text { urbanização }\end{array}$ & $\begin{array}{c}\text { Diversificação } \\
\text { da matriz } \\
\text { energética }\end{array}$ & $\begin{array}{l}\text { Indústria, } \\
\text { transportes }\end{array}$ \\
\hline $\begin{array}{l}\text { Tecnologias } \\
\text { e fontes } \\
\text { primárias } \\
\text { de maior } \\
\text { destaque }\end{array}$ & Pequenas usinas & Distribuição & $\begin{array}{l}\text { Transmissão } \\
\text { interligada, } \\
\text { geração de } \\
\text { grande escala }\end{array}$ & $\begin{array}{c}\text { Desverticalização } \\
\text { G/T/D/C, } \\
\text { diversificação, } \\
\text { combustíveis } \\
\text { fósseis (gás natural) }\end{array}$ & $\begin{array}{l}\text { Fontes renováveis } \\
\text { (eólica, solar } \\
\text { fotovoltaica, } \\
\text { biomassa) }\end{array}$ \\
\hline
\end{tabular}

\section{FIGURA 1}

ESTRUTURA INSTITUCIONAL DO SETOR ELÉTRICO - BRASIL

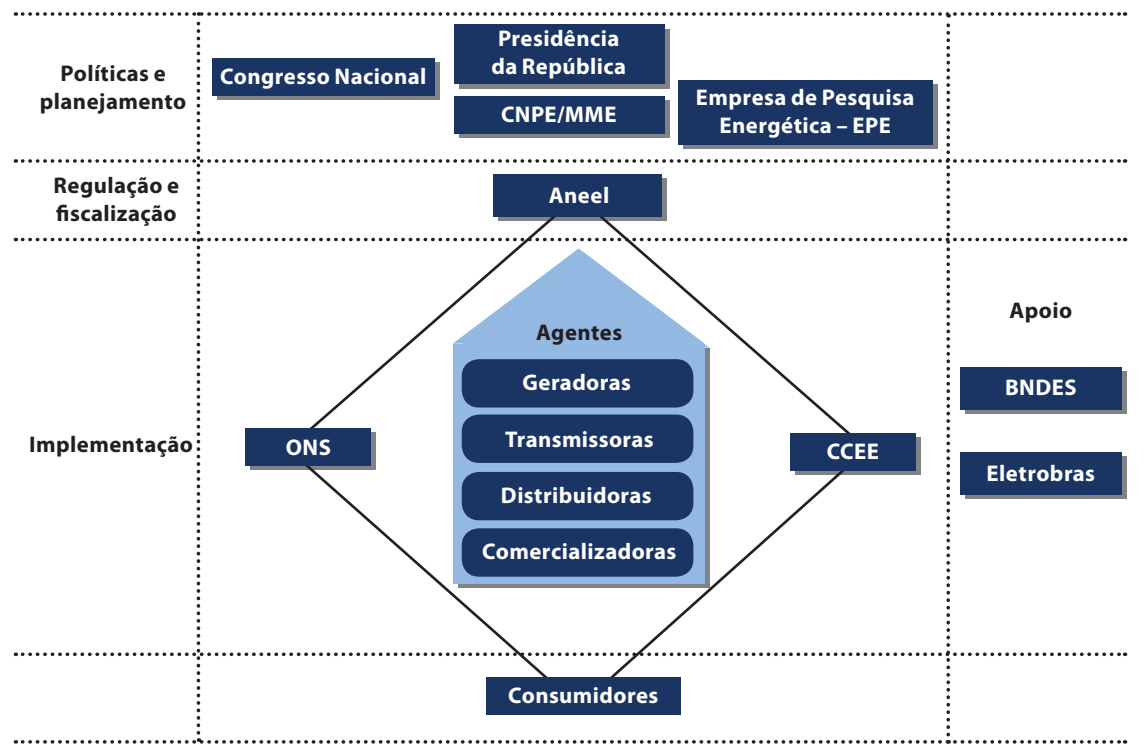


O problema do planejamento em um sistema complexo como o brasileiro, com um parque de geração diversificado, hidrotérmico, embora majoritariamente hidráulico, e uma malha de transmissão interconectada, envolve não apenas a expansão da capacidade instalada para garantir $\mathrm{o}$ atendimento à totalidade da demanda, mas também a coordenação da operação, pois as decisões sobre a operação do sistema estão acopladas no tempo e também no espaço em função da interligação das bacias e reservatórios e sua multiplicidade de proprietários e usos. Para o planejamento da expansão, o conhecimento da capacidade energética do sistema é fundamental e, para este, o planejamento da operação e suas regras são determinantes. Assim, o planejamento da operação e o da expansão guardam uma estreita relação (figuras 2 e 3 ).

\section{O PLANEJAMENTO DA EXPANSÃO E}

\section{DA OPERAÇÃO NO PERÍODO ANTERIOR À ORGANIZAÇÃO SETORIAL -}

\section{ATÉ MEADOS DOS ANOS 1960}

A condução privada do suprimento de energia à sociedade brasileira se estendeu por um longo período, desde a implantação dos primeiros empreendimentos de geração de eletricidade e provimento de "serviços energéticos", como iluminação e força motriz, no início do século XX. À medida que o caráter de prestação de serviço a um público crescente - industrial, comercial e residencial -, incluindo geração e distribuição, foi intensificado, a intervenção estatal foi-se fazendo necessária, como forma de mitigar a crônica falta de investimento das concessionárias em aumento da capacidade de oferta, em sua maioria estrangeiras, no mercado doméstico. Nesse período, não havia uma política de expansão setorial, uma vez que os contratos de concessão eram firmados diretamente com municípios e estados, e as decisões eram tomadas de acordo com as características de cada empreendimento e de cada empresa. Não havia uma visão integrada de planejamento, nem intercâmbio de informações, pois a atuação das concessionárias se dava de forma isolada, dentro de sua meta negocial. Além disso, a área de distribuição ia progressivamente se tornando mais importante, uma vez que era mais atraente, do ponto de vista econômico, para as empresas então estabelecidas. Ao Estado coube, então, a tarefa de organizar o setor e lidar com a necessidade premente de aumento da oferta de energia, mais complexa e mais intensiva em capital.

FIGURA 2

PLANEJAMENTO ENERGÉTICO - EXPANSÃO DA OFERTA

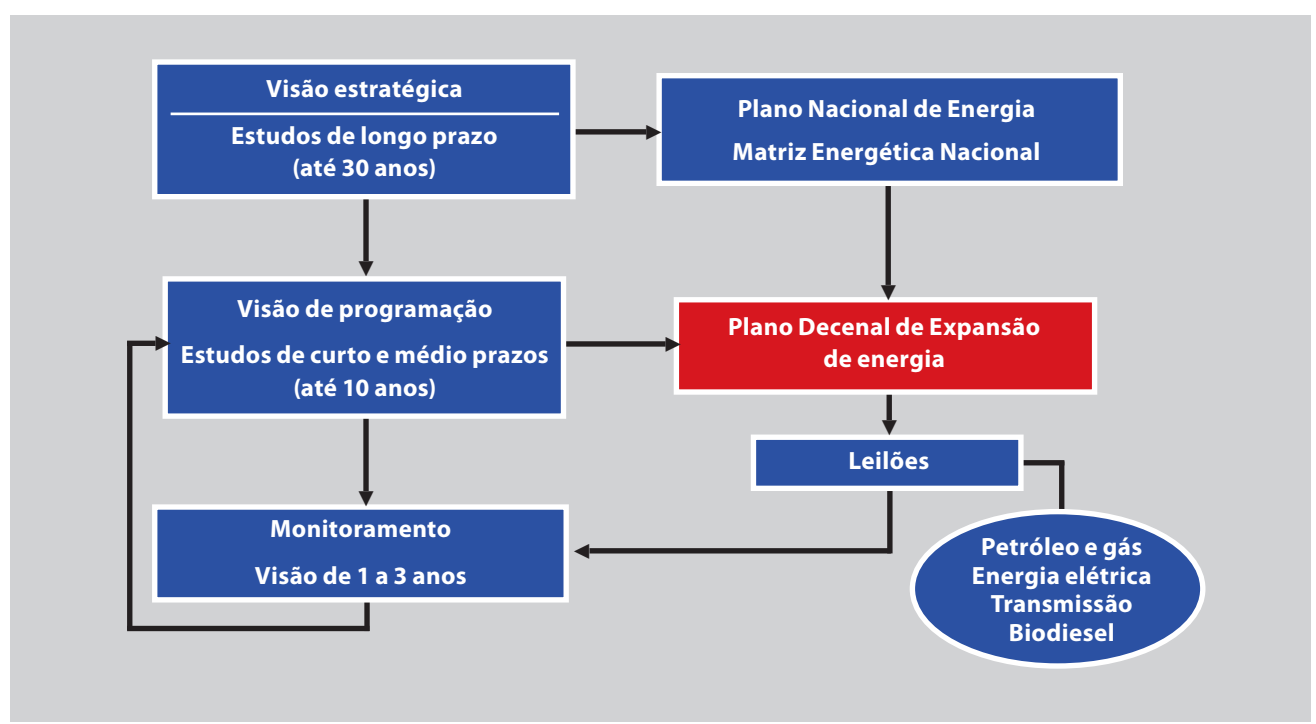

Fonte: Hollauer, 2011 


\section{PLANEJAMENTO ENERGÉTICO - DECOMPOSIÇÃO TEMPORAL DO PROBLEMA} DE COORDENAÇÃO DA OPERAÇÃO HIDROTÉRMICA DO SISTEMA BRASILEIRO

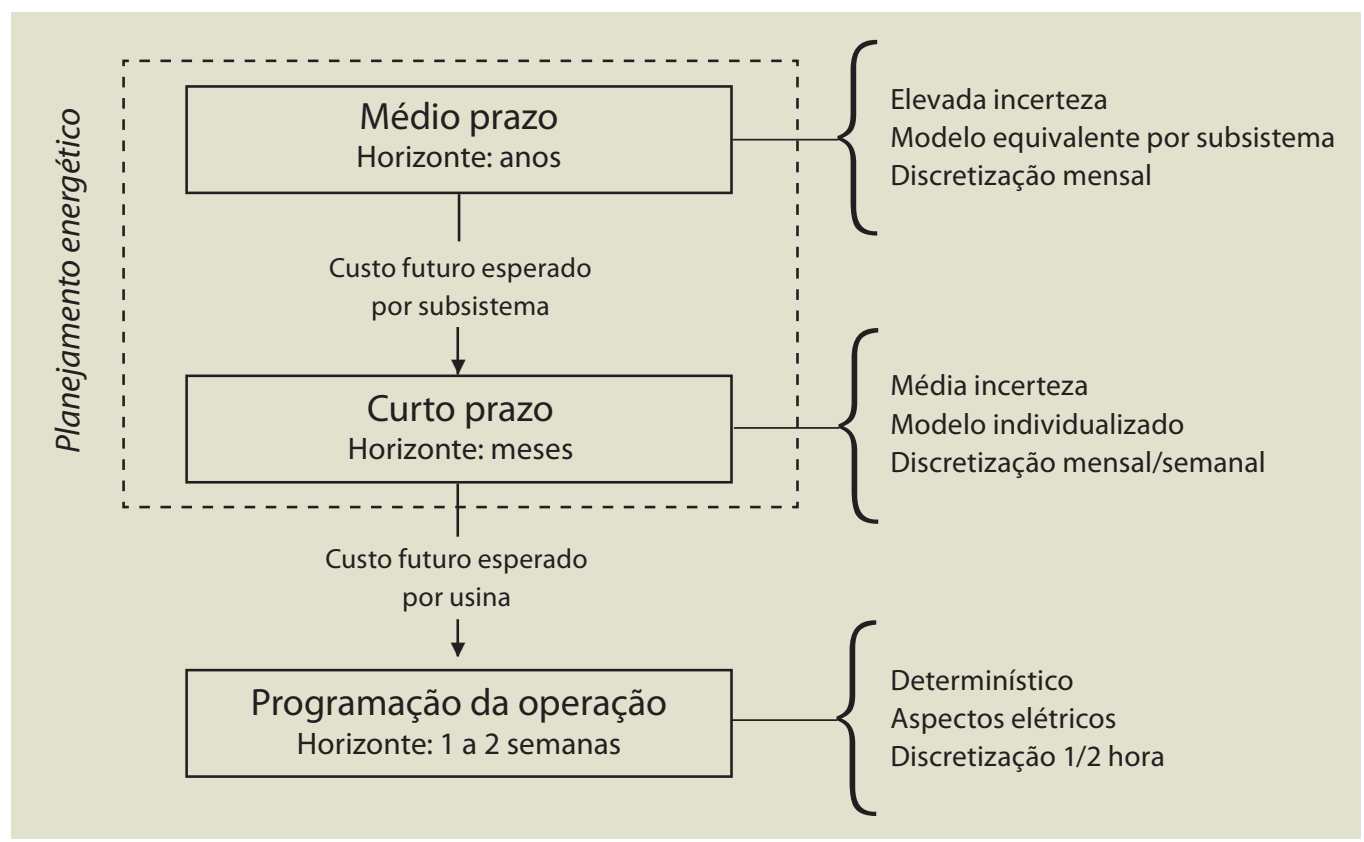

Fonte: Zambelli, 2006

Desde 1945, quando foi criada a Companhia Hidrelétrica do São Francisco - Chesf -, até 1979, quando foi comprada a Light, esse setor, que era $100 \%$ privado, tornou-se $98 \%$ público (Iannone, 2006; Mello, 1996). Durante esse período foram implantadas as indústrias brasileiras de base, como Companhia Siderúrgica Nacional (CSN), Petróleo Brasileiro S. A. (Petrobras), Banco Nacional de Desenvolvimento Econômico (posteriormente Banco Nacional de Desenvolvimento Econômico e Social - BNDES), Vale do Rio Doce, e houve o desenvolvimento da indústria automobilística nacional.

O período "desenvolvimentista”, voltado para a industrialização e urbanização do país, durou várias décadas. À medida que as metas dos sucessivos governos iam-se estabelecendo, em maior ou menor grau, a pressão sobre o sistema elétrico, então disperso, crescia. Porém, criavam-se as condições que levaram à organização institucional e centralização do planejamento do setor (Tabela 2). Quando a Eletrobras foi finalmente instalada, além de uma miríade de empresas privadas, já estavam em operação várias companhias estadu- ais estatais de energia elétrica e já estava criado o Ministério de Minas e Energia. A importância da Eletrobras para o planejamento se manteria até a reestruturação liberal, nos anos 1990 (Tabela 3).

A contratação do consórcio Canambra e o início das atividades da Eletrobras foram especialmente importantes para o estabelecimento e a consolidação de uma rotina de planejamento energético no país. A Canambra foi responsável pela realização do primeiro planejamento integrado de longo prazo e pela determinação detalhada, rio por rio, do potencial hidrelétrico do país. O trabalho da Canambra foi importante no levantamento da hidrologia, hidrometria e pluviometria do país junto às instituições existentes (Siqueira, 2001, in Eletrobras, 2001, p. 106). Quanto à Eletrobras, ao assumir o financiamento, a organização, o planejamento, a coordenação, a fiscalização e a operação do setor, tornou sistemática a atividade planejadora no Brasil, criando e mantendo a estrutura técnica e institucional necessária para que o país chegasse ao domínio da mesma, tanto na expansão da oferta, quanto na operação do sistema interligado (Figura 4). 


\section{SETOR ELÉTRICO - O PERÍODO KEYNESIANO ENTRE OS DOIS GOVERNOS VARGAS}

\begin{tabular}{|c|c|c|}
\hline Anos & Período & Principais eventos \\
\hline 1930 a 1945 & $\begin{array}{l}\text { Governo Vargas } \\
\text { Transição econômica, } \\
\text { social e política }\end{array}$ & $\begin{array}{l}\text { Economia nacional - de agroexportadora para industrial } \\
\text { - Expansão da oferta interna } \\
\text { - Substituição de importações } \\
\text { - Classe média urbana } x \text { valores rurais } \\
\text { - Nacionalismo } \\
\text { - Agregação dos centros fora do eixo Rio-São Paulo } \\
\text { Promulgação do Código de Águas e da Lei Oswaldo Aranha } \\
\text { (fim da Cláusula Ouro) } \\
\text { Poder concedente da energia elétrica - de local para federal } \\
\text { Prestação dos serviços públicos - fortemente regulada } \\
\text { Função do Estado predominantemente regulatória } \\
\text { Criação da Chesf }\end{array}$ \\
\hline \multirow{4}{*}{1945 a 1964} & $\begin{array}{l}\text { Governo Dutra } \\
(1946-1951)\end{array}$ & $\begin{array}{l}\text { Liberalismo econômico - industrialização c/ capital privado } \\
\text { Plano Salte (Saúde, Alimentação, Transportes, Energia) } \\
\text { Comissão Abbink }\end{array}$ \\
\hline & $\begin{array}{l}\text { Governo Vargas } \\
\text { (1951-1954) } \\
\text { governos interinos: } \\
\text { Café Filho (1954-1955); } \\
\text { Carlos Luz (1955-1955); } \\
\text { Nereu Ramos (1955-1956) }\end{array}$ & $\begin{array}{l}\text { Nacionalismo e intervenção } \\
\text { Comissão Mista Brasil-Estados Unidos } \\
\text { Industrialização crescente } x \text { infraestrutura deficitária } \\
\text { Criação de empresas estaduais (Cemig, CEEE...) } \\
\text { Projeto da Eletrobras (1954) - implantada em } 1962\end{array}$ \\
\hline & $\begin{array}{l}\text { Governo Juscelino } \\
(1956-1961)\end{array}$ & $\begin{array}{l}\text { Industrialização planejada: ápice - Plano de Metas } \\
\text { Capitais estrangeiros } \\
\text { Criação do Ministério de Minas e Energia } \\
\text { Criação de Furnas }\end{array}$ \\
\hline & $\begin{array}{l}\text { Governo Jango } \\
\text { (pós-Jânio - 1961-1964) }\end{array}$ & $\begin{array}{l}\text { Crise do desenvolvimentismo } \\
\text { Nacionalismo } \\
\text { Reformas sociais } \\
\text { Constituição da Eletrobras } \\
\text { Constituição do consórcio Canambra Engineering } \\
\text { Consultant Limited }\end{array}$ \\
\hline
\end{tabular}

Fonte: Mercedes, 2012

Até finais da década de 1970, o método utilizado para o planejamento da expansão esteve baseado no "período crítico", com o qual a análise de oferta de energia era feita supondo a repetição de uma série histórica de dados em que os anos mais secos correspondiam ao período 1952-56. As usinas eram dimensionadas de forma que a geração mínima cobrisse esse período crítico, e o resultado era denominado "energia firme" (Ventura Filho, 2001, in Eletrobras, 2001, p. 35; Eletrobras, 2002).

\section{O PERÍODO ELETROBRAS}

Nos primeiros anos de criação da Eletrobras, e de forma geral durante a década de 1960, a tarefa de planejamento passou para outras empresas, principalmente a Canambra, como já mencionado. Foi depois de 1967, quando foi inserida a Diretoria de Planejamento e Engenharia (DPE), que a Eletrobras passou a exercer a liderança das atividades de planejamento. Em 1967 foram rea- 


\section{TABELA 3}

\section{FORMAÇÃO E TRAJETÓRIA DA ELETROBRAS ATÉ A LIBERALIZAÇÃO DO SETOR ELÉTRICO}

\begin{tabular}{|c|c|}
\hline Período & Eventos \\
\hline $\begin{array}{l}\text { Década de } 1950 \\
\text { (segundo governo } \\
\text { Vargas) - fase de } \\
\text { conflitos e postergação } \\
\text { da criação }\end{array}$ & $\begin{array}{l}\text { Ambições de industrialização } \rightarrow \text { necessidade de infraestrutura } \\
\text { Demanda social de energia não atendida e crescente } \\
\text { Concessionárias privadas = falta de planejamento e escassez de investimentos } \\
\text { Instrumentos políticos e burocráticos } \\
\text { - CMBEU - Comissão Mista Brasil-Estados Unidos/PNE - Plano } \\
\text { Nacional de Eletrificação/IUEE - Imposto Único sobre Energia Elétrica/FFE - } \\
\text { Fundo Federal de Eletrificação } \\
\text { Projeto de lei da Eletrobras - apresentado em } 1954 \text { e aprovado em } 1961 \text { - início } \\
\text { das atividades em } 1962 \text { (João Goulart) } \\
\text { Criação das empresas estaduais de energia }\end{array}$ \\
\hline $\begin{array}{l}\text { Década de } 1960 \text { - } \\
\text { aumento da } \\
\text { complexidade e } \\
\text { expansão do sistema }\end{array}$ & $\begin{array}{l}\text { Criação do MME (JK) } \\
\text { Furnas - início da integração do setor } \\
\text { DNAEE - regulação (normalizadora e fiscalizadora) + Eletrobras - execução } \\
\quad \text { (expansão da geração e extensão geográfica do atendimento) }\end{array}$ \\
\hline $\begin{array}{l}\text { Década de } 1970- \\
\text { fortalecimento } \\
\text { da Eletrobras }\end{array}$ & $\begin{array}{l}\text { Reagrupamento das supridoras regionais - Eletrosul, Eletronorte, Chesf, Furnas } \\
\text { Reorganização das concessionárias estaduais - todas sob a Eletrobras } \\
\text { Criação do GCOI - Grupo Coordenador para a Operação Interligada } \\
\text { Reforma Campos-Bulhões e capacidade de autofinanciamento }\end{array}$ \\
\hline $\begin{array}{l}\text { Década de } 1980 \text { - } \\
\text { crise internacional } \\
\text { do capital }\end{array}$ & $\begin{array}{l}\text { Corrosão da estrutura de financiamento; contenção tarifária; conflito entre } \\
\text { Eletrobras e concessionárias } \\
\text { Criação do GCPS - Grupo Coordenador do Planejamento dos Sistemas Elétricos } \\
\text { Revise - Revisão Institucional do Setor Elétrico } \\
\text { Ressurgência do pensamento liberal - Pinochet, Thatcher, Reagan... }\end{array}$ \\
\hline $\begin{array}{l}\text { Década de } 1990- \\
\text { privatização e } \\
\text { "esvaziamento } \\
\text { institucional" } \\
\text { da Eletrobras }\end{array}$ & $\begin{array}{l}\text { Collor e PND } \\
\text { Operação desmonte }\end{array}$ \\
\hline
\end{tabular}

Fonte: Mercedes, 2012

lizados estudos da Região Sul com a condução da Canambra e a supervisão do Comitê Coordenador de Estudos Energéticos da Região Sul; cada região tinha seu próprio comitê coordenador. Em 1968 a Eletrobras iniciou estudos de mercado da Região Sudeste por solicitação do Banco Mundial para rever os estudos feitos pela Canambra e estruturar a liberação de empréstimos para o setor.
A tarefa finalizou em 1969 com o Power Market Study and Forecast - South Central Brazil (Eletrobras, 2002). Esse seria o ponto de partida para a elaboração de planos de expansão setorial por parte da Eletrobras.

A complexidade do projeto Itaipu e a construção dos grandes troncos de transmissão entre regiões, assim como o Tratado de Itaipu, 


\section{ESTRUTURA INSTITUCIONAL DO SETOR ENERGÉTICO NO FINAL DOS ANOS 1980 - BRASIL}

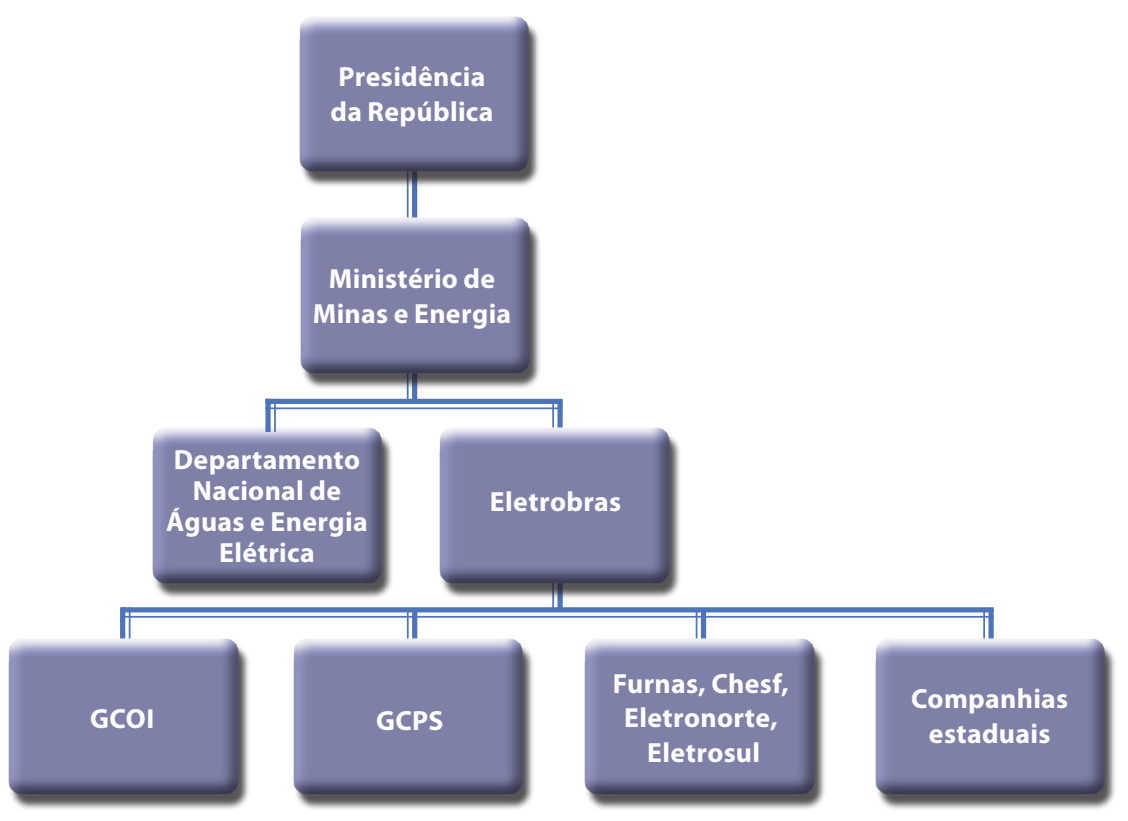

Fonte: Mercedes, 2002

introduziram uma nova forma de planejamento na operação das regiões Sudeste e Sul do país (Kligermann, 2009). A Lei no 5.899, de 1973, conhecida como Lei de Itaipu, reforçou as ações da Eletrobras como coordenadora do planejamento e da operação do sistema brasileiro. A partir dessa lei foram criados os Grupos Coordenadores de Operação Interligada - GCOIs com o fim de utilizar da melhor forma possível os recursos hidrotérmicos e abrir possibilidade de uma operação estratégica para o sistema interligado (Kligermann, 2009). Com a introdução dos sistemas interligados surgiu a necessidade de substituir o critério determinístico e inserir a análise probabilística.

Até 1974 as funções de operação, de planejamento e engenharia estavam sob a mesma diretoria da Eletrobras. Posteriormente, devido aos processos de industrialização do país e à demanda do próprio sistema, a área de operação foi separada e foi criado o Comitê Coordenador de Operação Interligada-CCOI, precursor dos GCOIs. As outras duas seções ficaram divididas em quatro departamentos: de estudos de mercado, de transmissão, de geração de energia e de estudos energéticos, este último precursor do Grupo Coordenador de Planejamento dos Sistemas Elétricos -GCPS (Eletrobras, 2002, p. 16).

O primeiro choque do petróleo influiu na elaboração do Plano 90, que não só considerou o sistema brasileiro como único e projetou principalmente o uso do recurso hidráulico para a geração de energia, mas também introduziu a ideia da substituição entre fontes. A inserção de usinas nucleares foi apresentada como planejamento especulativo, mas posteriormente foi apresentada no planejamento determinístico. Houve três cenários de projeção da demanda: o baixo, o médio e o alto, e como justificativa do programa nuclear foi criado o cenário de "mercado alto mais provável" (Camozzato, I, 2000, in Eletrobras, 2001, p. 83). Ainda nesse plano não havia as técnicas suficientes para simular os reservatórios e se optou pela regra de esvaziar primeiro o reservatório cujo metro cúbico gerasse a maior quantidade de energia ao longo da cascata do rio.

"Esta proposta foi substituída depois pela liberação da vazão do reservatório que mais gerasse na cadeia, somente até um ponto, denominado 'fai- 
xa'. Esse primeiro reservatório seria barrado nesse ponto e liberado o seguinte, até que todos utilizassem a primeira faixa, reiniciando-se todo o processo" (Camozzato, 2000, in Eletrobras, 2001, p. 83).

Em 1977 foi elaborado o primeiro plano nacional de energia elétrica, conhecido como "Plano 92" ou Plano Nacional de Atendimento aos Requisitos de Energia Elétrica até 1992, com o objetivo de proporcionar diretrizes de ordem econômica e técnica para a DPE da Eletrobras. Foi o primeiro plano com visão da integração entre regiões e proporcionou subsídios pra o Plano 95. O Plano 95, elaborado em 1979, foi considerado o primeiro plano de expansão territorial e tinha dados mais precisos do potencial hidrelétrico brasileiro. Esse foi um plano de médio prazo com horizonte de 15 anos, levando em conta os prazos de construção das usinas e das linhas de transmissão (Eletrobras, 2002).

Em 1977, a Eletrobras e o Centro de Pesquisas de Energia Elétrica (Cepel) completaram um modelo de programação dinâmica estocástica (PDE) que determinava a cada mês o despacho hidrotérmico de menor custo (Terry et al., 1986). O objetivo através do modelo era introduzir no planejamento do setor a dinâmica estocástica para agregar componentes estatísticos e projetar várias opções que cobririam todas as vazões possíveis. Em lugar de considerar o pior cenário ocorrido na série histórica de vazões, agora seriam tirados alguns índices do histórico, como, por exemplo, a média, o desvio padrão e a correlação temporal das vazões medidas, e seriam introduzidos no modelo PDE que simulava mensalmente o montante de geração térmica para obter o mínimo custo no horizonte desejado com todas as possibilidades de afluência (Kligermann, 2009; Terry et al., 1986). O GCOI criou um grupo de trabalho com representantes das concessionárias pra analisar o novo modelo e definir critérios para sua aplicação na operação do sistema (Eletrobras). Os critérios para uso do modelo nos estudos de operação do sistema foram estabelecidos em 1979, e o modelo PDE foi usado para determinar a estratégia de operação e índices de confiabilidade nos planos de expansão (Terry et al., 1986).

Na década de 1980, o Estado começou a ser desacreditado e responsabilizado pela degradação das taxas de crescimento do período keynesiano.
Era o ressurgimento da economia neoliberal e a implantação de reformas estruturais na maioria dos países da América Latina. O planejamento centralizado começou a ser questionado. Com o objetivo de dar um caráter sistemático ao planejamento, mas também com fins representativos dos diversos interesses das empresas estaduais, em novembro de 1980 foi criado o GCPS. Dois anos depois, mediante a Portaria no 1.617 de 1982, o GCPS foi reconhecido como organismo responsável pela expansão dos sistemas elétricos brasileiros. Um grupo importante, pertencente ao GCPS, foi o grupo de trabalhos de critérios de planejamento energético, o qual fez a difusão dos critérios de planejamento e criou um ponto de partida para introduzir a análise probabilística para a expansão do sistema. O planejamento do setor elétrico brasileiro esteve em mãos do GCPS até 1995.

Em 1984, o GCPS programou trabalhos de revisão do planejamento de médio e longo prazo, entre os quais a avaliação do critério usado na garantia de fornecimento. Esse trabalho foi encomendado para um subgrupo com representantes do GCPS e do GCOI. As concessionárias estavam implementando o modelo de programação dinâmica estocástica desde 1979, que permitiu a introdução da análise probabilística no planejamento da expansão. Esse método possibilitou calcular o nível de risco no atendimento da demanda. O risco anual de déficit aceitável foi de 5\%, e o planejamento da expansão e operação dos sistemas interligados passou a considerar esse risco de déficit para avaliar a disponibilidade de energia (Eletrobras, 2002, p. 219; Eletrobras, 2001, p. 37).

Em 1985, com o início do governo Sarney, iniciava-se a redemocratização e a transição entre o modelo intervencionista militar e o modelo liberal. Nesse governo foi aprovado o Plano de Recuperação Setorial (PRS), com a supervisão da Eletrobras e a participação das empresas concessionárias e o Departamento Nacional de Águas e Energia Elétrica - DNAEE. Esse plano continha os planos e obras a ser executadas até 1989 , no entanto, os trâmites de negociação da dívida externa e os conflitos entre as concessionárias pelos recursos disponíveis frearam esse processo, somados às reformas promovidas nos setores de infraestrutura, obedecendo ao preceito de priorizar aqueles de caráter estratégico e rentabilidade assegurada (Mercedes, 
2012). Outra das recomendações do PRS foi a revisão do Plano 2000 em 1985, um ano antes do previsto. O aporte do Plano 2000 esteve determinado pela inserção de outros setores no planejamento do setor elétrico, e as restrições da época fizeram com que o equilíbrio econômico-financeiro fosse uma das considerações mais importantes. A partir desse plano, os seguintes seriam uma revisão do anterior. O Plano 2010, Plano Nacional de Energia Elétrica 1987-2010, nasce em 1986 como revisão do Plano 2000.

O Plano 2010 incluiu os recursos hídricos da Amazônia, usinas termelétricas e reintroduziu as usinas nucleares do Plano 90. Outro dos pontos foi a introdução do licenciamento das atividades que afetam o meio ambiente através do estudo de impacto ambiental e o respectivo "Relatório de Impacto Ambiental EIA-Rima" a partir de 1986. O Plano 2010 foi aprovado em 1988 como "balizador do atendimento ao mercado de energia elétrica", mas, ao mesmo tempo, o GCPS foi responsabilizado por elaborar a expansão de curto prazo com os Planos Decenais de Expansão (Eletrobras, 2002). O primeiro deles foi o Plano de Expansão 1990-99 com projeções de PIB e de crescimento do sistema inferiores às propostas no Plano 2010 como consequência das modificações estruturais que estaria sofrendo a economia. Os cronogramas propostos no Plano 2010 foram postergados para ajustar a oferta com o mercado de energia. A entrada de obras como Belo Monte era incompatível com os recursos do setor, assim como a usina Ilha Grande (Eletrobras, 2002).

O Plano 2010 foi dos primeiros a considerarem a redução das incertezas no planejamento de longo prazo. Na visão do GCPS, o planejamento de longo prazo, mais que acertar uma previsão, devia estabelecer uma referência, dado o caráter dinâmico do setor, e permitir a efetividade das ações frente a diferentes situações de mercado ou de suprimento. O Plano 2010 indicou a possibilidade de uso do modelo de evolução de mercado de demanda de energia (Medee) elaborado na França, que era um modelo contábil das necessidades energéticas da sociedade (Eletrobras, 2002, p. 250). Por sua parte, a Eletrobras, desde 1983, vinha desenvolvendo um modelo de programação lineal para a criação e análise de cenários baseado no custo mínimo de investimentos e operação denominado Markal, que já era utilizado em outros países para a avaliação dos sistemas energéticos. Porém, as estratégias calculadas por PDE para cada reservatório equivalente eram implementadas através do modelo Baltroc, que simulava os intercâmbios de fluxo de energia entre as regiões Norte e Nordeste e Sul e Sudeste/ Centro-Oeste com base em balanços com trocas empíricas (Kligermann, 2009). A partir de 1983 foi implementado o modelo Bacus, que utilizava o valor de água de cada subsistema para as trocas de energia, mas não levava de forma explícita os intercâmbios, motivo pelo qual não era bem avaliado, mas ao final era aceito de forma consensual. Somente a partir de 1998, quando foi introduzido o modelo Newave, foram considerados os intercâmbios entre subsistemas através da programação dinâmica dual estocástica (Kligermann, 2009).

\section{A PRIMEIRA FASE DA LIBERALIZAÇÃO - FHC}

Em um contexto regional de implantação de ajustes de caráter liberal à economia, o Brasil também promoveu reformas nos setores de infraestrutura, obedecendo ao preceito de priorizar aqueles de caráter estratégico e rentabilidade assegurada. Especificamente em relação ao setor energético, a reestruturação tinha objetivos bastante definidos, considerando sua importância em termos de organização e crescimento econômico dos países. Esses objetivos incluíam (Mercedes, 2012b):

- Mercantilizar o serviço público de fornecimento de energia.

- Remover os entraves à "globalização" da indústria energética, permitindo o livre trânsito dos capitais internacionais, segundo seus interesses.

- Promover a ideologia da eficiência econômica: o setor privado é mais eficiente em promover alocação de recursos do que o setor público; o incremento de competição e a desregulamentação levam à eficiência econômica; políticas orientadas pelo mercado criam verdadeiras pressões democráticas sobre a gestão do sistema, pois a escolha econômica individual é a única autêntica expressão da liberdade na sociedade; somente a liberalização levaria à eficiência ambiental, por levar à abolição de tecnologias obsoletas. 
O governo Collor, que figura como o responsável pelo início da abertura econômica, apesar da retórica modernizante, não adotou logo de início as reformas liberais. $\mathrm{O}$ marco definitivo para a implantação dos ajustes foi estabelecido no governo seguinte, de Fernando Henrique Cardoso. Este sofisticou e acelerou o Programa Nacional de Desestatização (já implantado), endureceu a política de ajustes fiscais e estabilidade monetária e adotou o regime de âncora cambial, uma das premissas do Consenso de Washington. O setor elétrico foi amplamente reestruturado. O novo modelo foi elaborado pela consultoria inglesa Coopers \& Lybrand, desconsiderando características fundamentais do sistema brasileiro (Figura 5). As reformas são sintetizadas na Tabela 4, comparadas às estruturas do modelo anterior, estatal.
Como mencionado, ao instituir o GCPS e o GCOI, a indústria elétrica brasileira tinha praticamente completado seu arcabouço institucional. Os dois órgãos responsabilizavam-se, respectivamente, por elaborar o Plano de Expansão e o Plano de Operação do Sistema. Pelas características da geração, essencialmente hidráulica e baseada no aproveitamento das complementaridades hidrológicas das bacias ao longo do país, tanto a expansão quanto a operação dependem, ainda, de uma interação cooperativa entre agentes a fim de que não se percam suas principais vantagens: maior confiabilidade associada ao menor custo econômico.

Trabalhando simultaneamente com os dados de mercado e com as condições hidrológicas das bacias (por exemplo, critérios probabilísticos de

\section{TABELA 4}

\section{MODELO ESTATAL X MODELO LIBERAL}

\begin{tabular}{|c|c|}
\hline Modelo estatal & Modelo liberalizado (1 ${ }^{a}$ fase) \\
\hline $\begin{array}{l}\text { Preços de geração regulamentados e contratos } \\
\text { de suprimento renováveis }\end{array}$ & MAE - mercado atacadista de concepção mercantil \\
\hline $\begin{array}{l}\text { Empresas integradas atuando em regime de } \\
\text { monopólio }\end{array}$ & $\begin{array}{l}\text { G, T, D e C como atividades independentes e limites } \\
\text { à participação cruzada }\end{array}$ \\
\hline Transmissão de energia agregada à geração & $\begin{array}{l}\text { Malhas de transmissão/conexão e distribuição } \\
\text { desagregadas e permitindo livre acesso }\end{array}$ \\
\hline Mercados cativos & $\begin{array}{l}\text { Consumidores cativos + aumento gradual de livres }+ \\
\text { liberação paulatina }\end{array}$ \\
\hline GCPS e planejamento normativo & CCPE e planejamento indicativo \\
\hline \multicolumn{2}{|l|}{ Planos decenais } \\
\hline GCOI e condomínio de mercado & ONS operacionalizando mercado competitivo \\
\hline $\begin{array}{l}\text { Tarifa via serviço pelo custo e remuneração } \\
\text { garantida até } 1993\end{array}$ & $\begin{array}{l}\text { Tarifa regulada para consumidores cativos e preços } \\
\text { competitivos e desregulamentados para livres } \\
\text { e suprimento }\end{array}$ \\
\hline $\begin{array}{l}\text { Aprovação dos serviços públicos de energia pelo } \\
\text { DNAEE }\end{array}$ & $\begin{array}{l}\text { Concessões licitadas pela Aneel; todos os } \\
\text { aproveitamentos considerados como PIE }\end{array}$ \\
\hline $\begin{array}{l}\text { Restrição à atuação de autoprodutores e } \\
\text { produtores independentes }\end{array}$ & $\begin{array}{l}\text { Regulamentação da atuação de autoprodutores e PIE } \\
\text { e permissões de livre acesso à rede }\end{array}$ \\
\hline
\end{tabular}

Fonte: Sauer, 2003 


\title{
FIGURA 5
}

\section{FLUXOGRAMA DAS ETAPAS DE REESTRUTURAÇÃO E DESESTATIZAÇÃO DO SETOR ELÉTRICO}

\author{
1. Antecedentes \\ - Modelo de financiamento entra em crise em 1981 \\ - Tentativa de revitalizar o setor em 1987 (PRS) \\ - Tentativas de reformação do setor em 1986-88 (Revise)

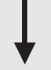 \\ Perío do de impasse e imobilismo \\ (perda da capacidade de investimento do setor)
}

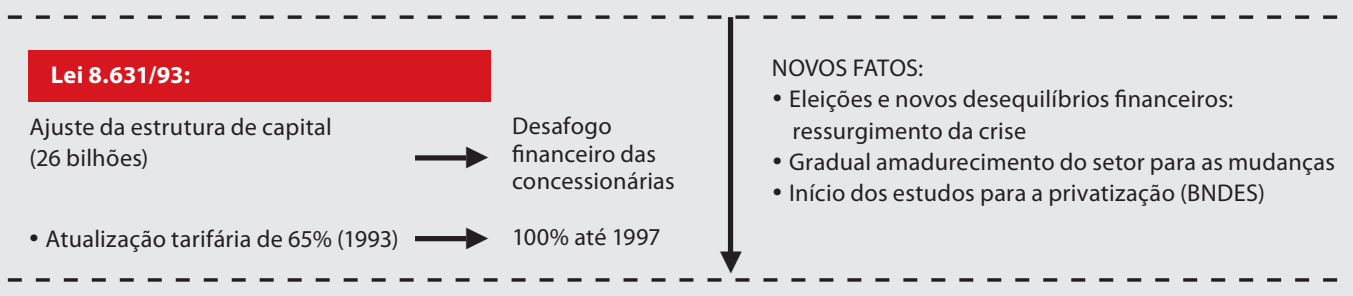

2. Políticas e ações do governo Fernando Henrique Cardoso

Sob a ameaça de crise de suprimento pela falta de investimentos e hidrologia desfavorável (até 1996):

2.1 Bases da reestruturação:

$$
\begin{aligned}
& \text { Lei das concessões } 8.987 \text { e 9.074/95 } \\
& \text { - Licitação } \\
& \text { - Competição na geração } \\
& \text { - Livre acesso à rede de transmissão } \\
& \text { - Escolha livre do superior de energia }
\end{aligned}
$$

2.2 Desafio duplo: promover uma reestruturação consistente e duradoura e, ao mesmo tempo, expandir o mercado ("O MERCADO NÃO ESPERA PELAS MUDANÇAS")

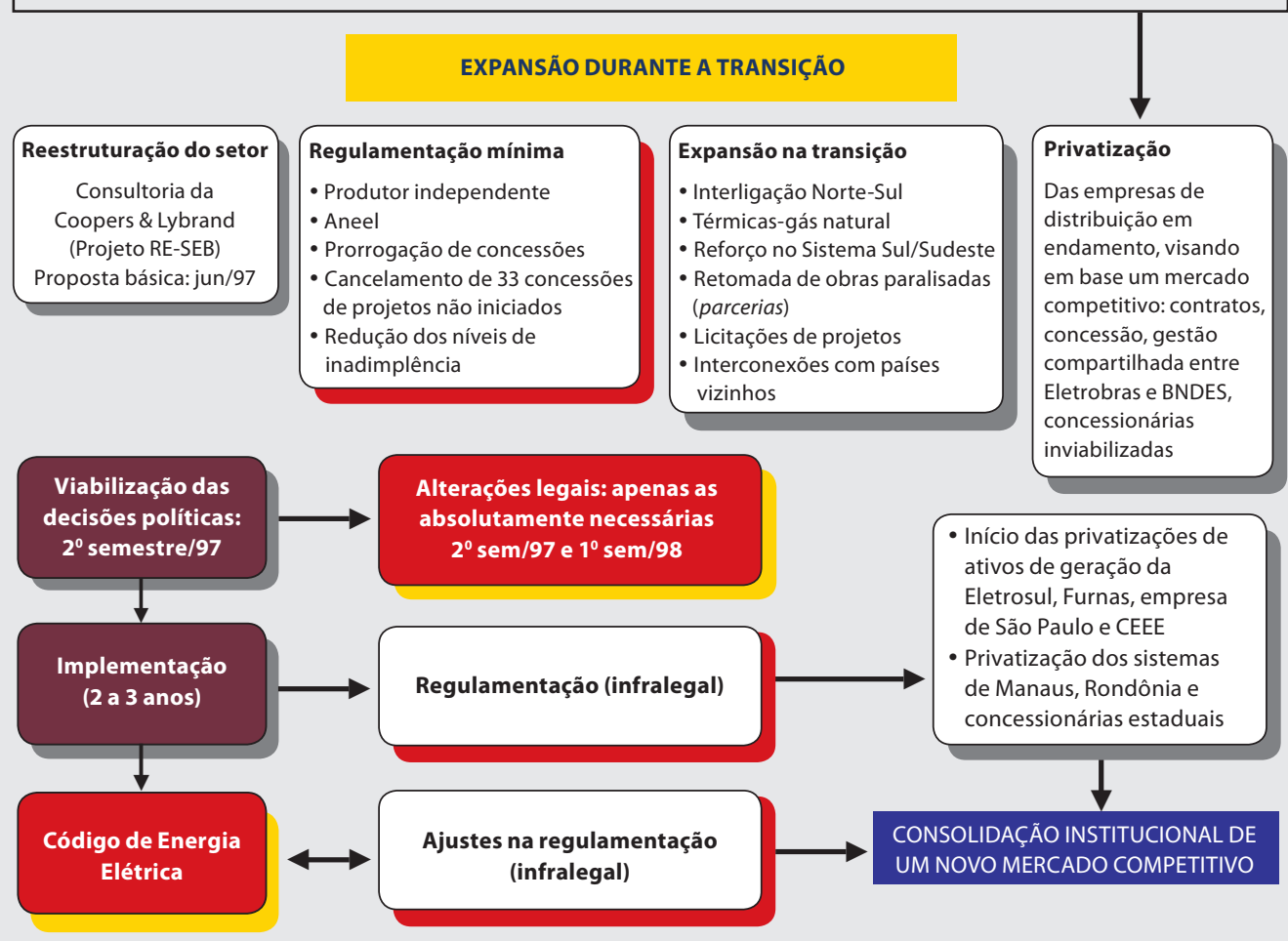

Fonte: Brasil, 1998 
risco de déficit, nível de armazenamento dos reservatórios), as duas entidades buscavam assegurar o mínimo risco de desabastecimento, tanto no longo prazo (expansão), quanto no curtíssimo prazo (operação). Do planejamento provinham, ainda, os custos marginais de expansão da geração, da transmissão e da operação, que balizavam tanto a tarifação, quanto o despacho otimizado (Oliveira et al., 1999). Durante o período FHC, o planejamento da expansão passou a ser efetuado pelo Comitê Coordenador do Planejamento da Expansão dos Sistemas Elétricos (CCPE) e a operação coube ao Operador Nacional do Sistema (ONS), que manteve sua função na reforma Lula-Dilma.

No âmbito do CCPE, importantes alterações foram introduzidas com a adoção do modelo liberalizado. De imediato, o fluxo de informações, antes compartilhado abertamente por todos os agentes, passou a ser tratado como de importância estratégica comercial pelos agentes privatizados, e não mais disponibilizado com a transparência de antes. O planejamento, que tinha caráter normativo, baseado nas premissas supramencionadas, passou a ser indicativo, fornecendo critérios técnicos e econômicos para que os agentes decidissem, de acordo com seus próprios interesses, o que era mais vantajoso empreender. Finalmente, passou a existir a tarefa política de assegurar um mínimo planejamento necessário à prestação de um serviço público, diante de atores privados, com programações próprias, não necessariamente produzidas no país (orientações vindas das matrizes, dentro de contextos supranacionais) (Mercedes, 2002).

O ONS, entidade civil de direito privado, substituiu o GCOI, mantendo praticamente todas as suas funções. De forma pitoresca, o exercício de tais funções era apresentado, como peça de publicidade institucional, como uma vantagem para a sociedade. Ao contrário do CCPE, que se apoiava, ainda, sobre a capacidade técnica acumulada da Eletrobras, no ONS ocorreu uma grande desarticulação de pessoal habilitado, que redundou, nos primórdios de sua implantação, num blecaute de proporções nacionais. No episódio da crise de abastecimento, embora o órgão tivesse conhecimento das graves consequências que decorreriam do deplecionamento dos reservatórios a fim de suplantar a falta de turbinas, até 2001, ao contrário do órgão que lhe deu ori- gem, nenhuma atuação (ou força) política teve no sentido de promover qualquer mudança de rumo na condução do problema, impedindo tal uso. Demonstrou ter-se tornado um órgão meramente executivo (Mercedes, 2002).

Além da perda de competência técnica, com o desmonte das principais áreas de planejamento e operação do sistema elétrico, do surgimento e ampliação dos custos de transação e custos regulatórios, da inadequação do modelo e falta de cultura regulatória, que permitiram abusos por parte dos novos concessionários e do aumento exponencial das tarifas, um evento ficou como a marca derradeira das reformas: o racionamento de energia ocorrido em 2001. Antes, vários blecautes, por má gestão, má operação e manutenção, com explicações, no mínimo pitorescas. A falta de investimentos em capacidade instalada e o fracasso do programa prioritário de termelétricas levaram ao deplecionamento dos reservatórios do Sistema Interligado Nacional (SIN) e culminaram no racionamento (Mercedes, 2012b).

O planejamento energético vem buscando, sobretudo nos últimos anos, após a liberalização dos setores de infraestrutura, resolver simultaneamente um problema prioritariamente técnico, vinculado à operação dos sistemas elétricos, e outro, que é econômico-financeiro, isto é, trata-se de obter um plano ótimo de operação que reduza os custos da energia, os riscos técnicos, de déficit, e os negociais, pois agentes privados atuam nesse setor. Buscando esse tipo de solução, tornou-se necessário dispor de modelos de programação cada vez mais robustos, o que foi permitido pelo avanço da computação e das teorias de modelagem (Lopes, 2007). No caso do sistema brasileiro, hidrotérmico, interligado, essa busca assumiu o caráter de prioridade quase absoluta.

Como relatam Lopes (2007) e Amaral (2003), o Cepel, pertencente ao sistema Eletrobras, e a Coppe tiveram importante papel no desenvolvimento do sistema que hoje domina completamente a operação e a precificação de energia no país: o Newave. Segundo os autores, uma vez que a Eletrobras já desenvolvia programas de modelagem desde o final da década de 1970 e a partir das primeiras propostas metodológicas na linha da programação dinâmica dual estocástica, elaboradas ainda na década de 1980 (Lopes, 2007), o 
Newave ganhou importância no setor no período da liberalização, mais especificamente a partir de 1999, enquanto seu complemento, o programa Decomp, passou a ser empregado a partir de 2001 (Amaral, 2003).

Destinado ao cálculo do custo marginal de operação do sistema, que, por sua vez, baliza o cálculo do preço a ser utilizado nas transações de curto prazo (mercado spot, no período liberalizado; de liquidação de diferenças, no presente) (Figura 6), o preço definido a partir do uso dos programas Newave e Decomp passou a balizar praticamente todas as transações que envolvem a energia elétrica no país. Uma vez que embute o risco representado pela estocasticidade decorrente da predominância hidráulica na geração, o seu uso levou ao estabelecimento de uma forte característica especulativa, com consequências que já se mostraram desastrosas para a sociedade brasileira.

\section{A SEGUNDA FASE DA}

\section{LIBERALIZAÇÃO - LULA E DILMA}

Os equívocos cometidos pelo governo anterior, que conduziram, no setor elétrico, ao racionamento de 2001, foram, como narra D'Araújo (2009, p. 191), o principal interesse ao longo da campanha presidencial do Partido dos Trabalhadores em 2002:

"Evidentemente, por ter sido a mais equivocada política pública do governo Fernando Henrique
Cardoso, a privatização das empresas e o modelo mercantil implantado foram alvo da campanha do então candidato Luís Inácio Lula da Silva. O Instituto Cidadania, entidade com óbvias relações com o Partido dos Trabalhadores, promoveu diversas reuniões com técnicos, que vinham apontando esses erros, mesmo aqueles sem ligações partidárias. Em julho de 2002, produziu um texto denominado 'Diretrizes e Linhas de Ação para o Setor Elétrico Brasileiro"”.

Esse documento, cuja elaboração foi coordenada por Pinguelli Rosa, no Instituto Cidadania, e foi realizada por uma equipe que incluía nomes como Ildo Sauer e o próprio Roberto D'Araújo, encerrava, em seu índice, uma hierarquia das ações e urgências que deveriam nortear a gestão setorial, caso a candidatura Lula fosse vitoriosa (Rosa, 2004), e que decorriam da necessidade de enfrentamento imediato e revisão profunda do modelo de liberalização plena, fracassado:

"I - Política Energética: implicações estratégicas. II - O Quadro Resultante da Crise e as Medidas do Governo.

III - Princípios Básicos de um Novo Modelo.

IV - Modelo de Serviço Público Integrando Empresas Elétricas Estatais e Privadas.

V - Diferenças entre o Modelo (anterior) e a Presente Proposta (novo modelo).

VI - Ações Imediatas para Superar a Crise".

\section{FIGURA 6}

\section{CÁLCULO DO CMO UTILIZANDO O NEWAVE E O DECOMP}

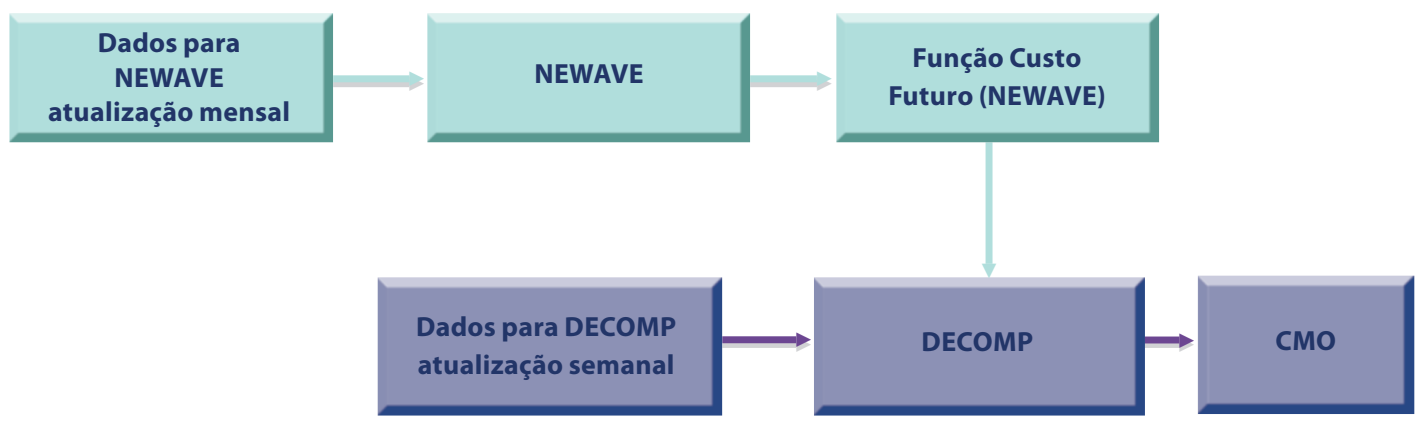


Além desse documento, o próprio programa de governo da campanha de 2002, sobre o setor elétrico, apontava:

"8. [...] O novo governo trabalhará com um planejamento energético integrado, de maneira a viabilizar novas dinâmicas para os setores de hidroeletricidade, petróleo e gás natural, carvão, de geração nuclear, fontes alternativas (eólica, solar e biomassa), de eficiência energética e cogeração e geração distribuída [...].

[...]

31. No nosso governo, as bases de sustentação dessa atividade não serão entregues apenas às forças do mercado nem a uma visão tecnocrática e autoritária, centralizadora. Devem ter caráter participativo, criando mecanismos de controle social e de incorporação de contribuições dos diversos segmentos da sociedade, dos consumidores residenciais, da indústria, da agricultura, do comércio e dos serviços. [...]

[...]

38. As ações básicas serão desenvolvidas no sentido de impedir a transferência de renda do setor energético; retomar os investimentos setoriais, alavancando os expressivos recursos próprios das empresas públicas e atraindo o capital privado para expansão do sistema; impedir a cisão de Furnas, Eletronorte e Chesf, orientando as empresas que se mantêm sob o controle da União e dos estados a reinvestirem na expansão, de acordo com a capacidade financeira de cada uma" (Palocci Filho \& Daniel, 2002).

Em março de 2003, já no governo Lula, Sauer lançou, em evento público na Universidade de São Paulo, a proposta de modelo institucional oriunda dos debates realizados no âmbito do grupo de pesquisa USP 1105, a mesma que levara para os debates do Instituto Cidadania e que apresentara, dias antes, ao governo empossado. Sua proposta, equivocadamente identificada como modelo single buyer, do Banco Mundial, previa, contudo, uma participação majoritária do Estado na apropriação da renda setorial, visando a sua redistribuição no próprio setor e em outras prioridades definidas em processos públicos e transparentes. Ainda assim, o modelo, aprimorado, foi proposto como major buyer (Figura 7).
Entretanto, o novo Ministério de Minas e Energia, encabeçado por Dilma, optou por desenvolver uma terceira proposta, baseada em arranjo, este sim, preconizado pelo Banco Mundial: multiple buyers, multiple sellers in bilateral markets (múltiplos compradores, múltiplos vendedores em mercados bilaterais) (figuras 8 e 9).

Pereira (2003) narra os eventos decorridos da disputa entre modelos, que marcou o primeiro ano do governo Lula:

"O Ministério de Minas e Energia, diz o seu secretário-geral, Maurício Tolmasquim, já se decidiu em relação à questão básica que emperrava a apresentação do novo modelo para a reestruturação do setor elétrico: entre o mercado e o planejamento optou pelos dois - vai tentar combinar um planejamento estatal determinativo com um modelo de geração, transmissão e distribuição baseado na competição e no mercado. No novo modelo, uma entidade - provisoriamente chamada de Administradora da Contratação de Energia (ACE) -, sob controle público, planejará e determinará as novas licitações necessárias para atender à demanda prevista.

A ACE tenta corrigir o principal e mais visível defeito do modelo herdado de Fernando Henrique Cardoso. Apoiado num planejamento apenas indicativo e nas iniciativas dos investidores privados, o modelo de inspiração neoliberal, que privatizou grande parte da distribuição e fracassou na implantação de um mercado livre de compra e venda de energia no país, não garantiu a instalação de novas usinas e linhas de transmissão com capacidade suficiente para suprir o consumo previsto, o que levou o país ao flagelo do apagão de 2001-2002.

A entidade pública anunciada, diz Tolmasquim, tentará induzir as distribuidoras a realizarem contratos de expansão do fornecimento dentro das previsões oficiais, mas suas avaliações serão determinativas, em última instância, apenas para ela própria. No modelo proposto para a ACE prevaleceu a opção de menor intervenção estatal possível: as distribuidoras de energia negociarão diretamente seus novos contratos de fornecimento com as geradoras e poderão divergir do planejamento oficial, contratando menor fornecimento por considerarem excessivo o consumo previsto. 


\section{FIGURA 7}

\section{PASSOS DO PLANEJAMENTO DETERMINATIVO NO MODELO PROPOSTO POR SAUER}

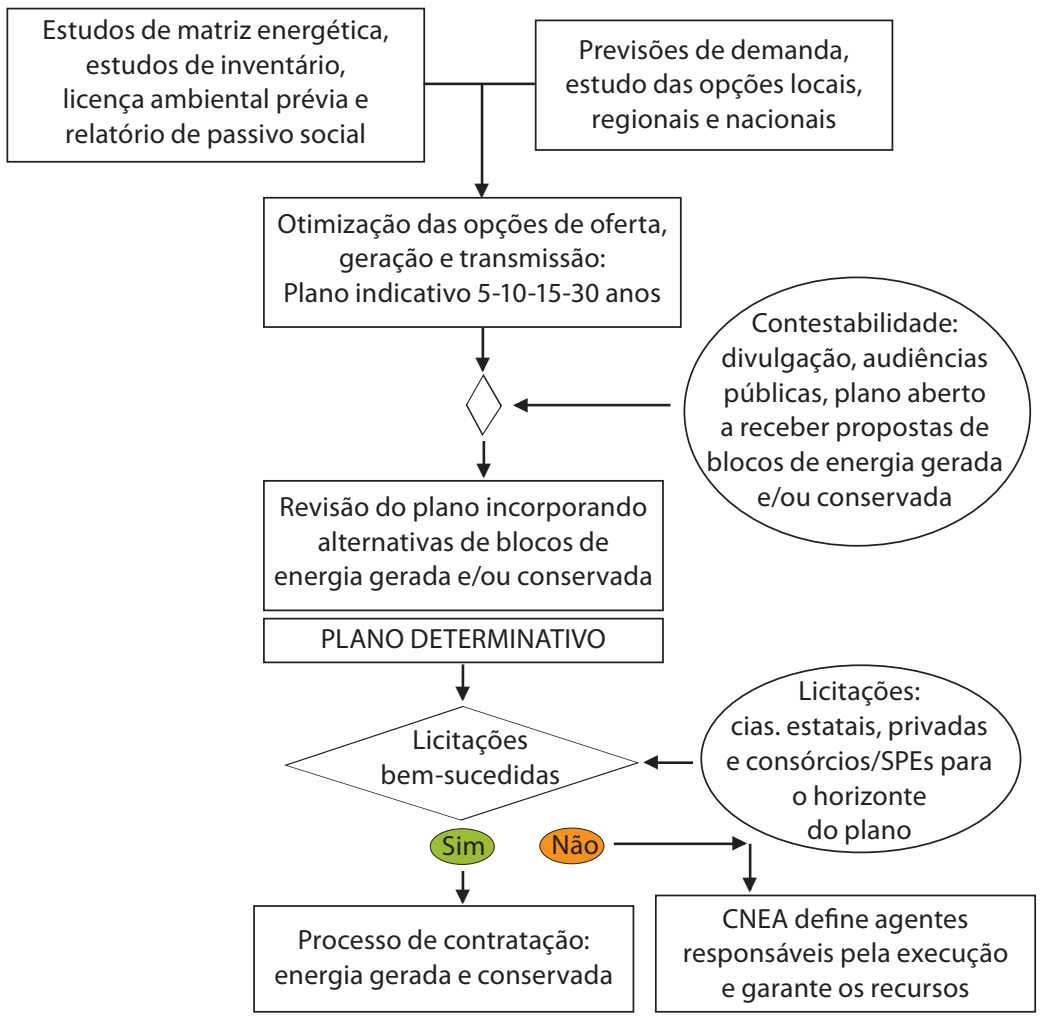

Fonte: Sauer, 2003

\section{FIGURA 8}

\section{MAJOR BUYER X MULTIPLE BUYERS, MULTIPLE SELLERS IN BILATERAL MARKETS (MULTICONTRATAÇÃO BILATERAL)}

\section{The bilateral contracts model for electricity trading}

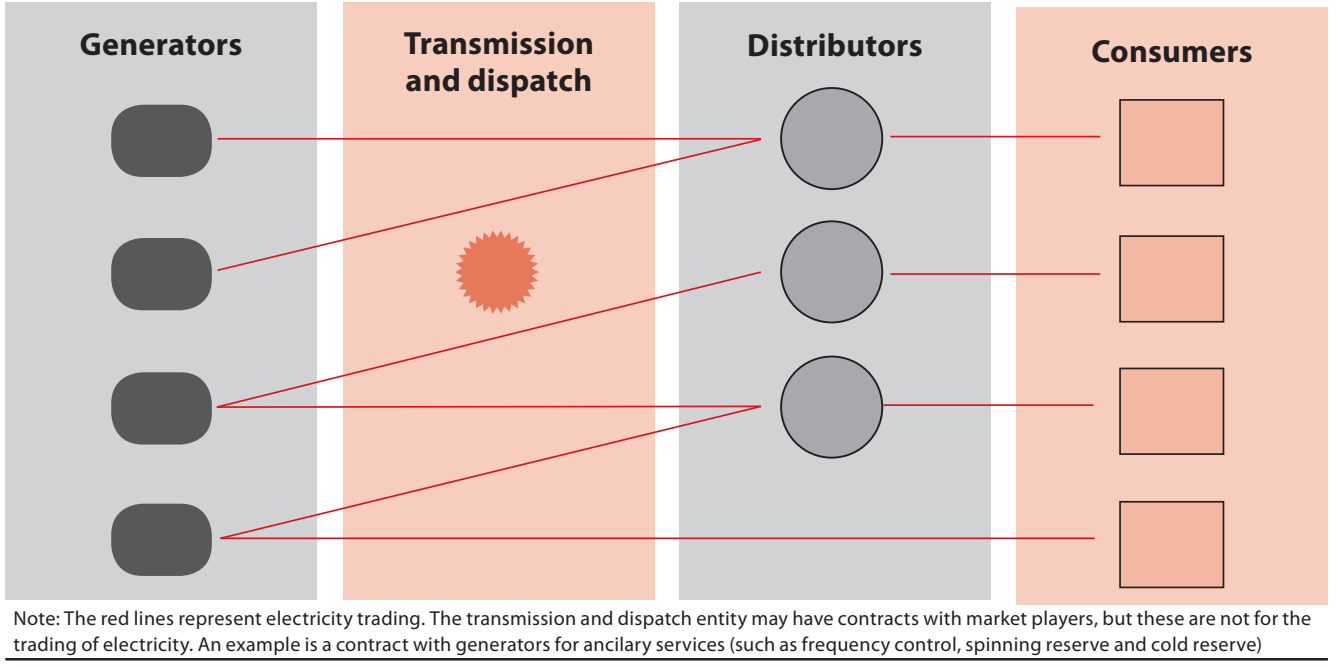

Fonte: Lovei, 2000 


\section{PROPOSTA DE MODELO INSTITUCIONAL PARA O SETOR ELÉTRICO}

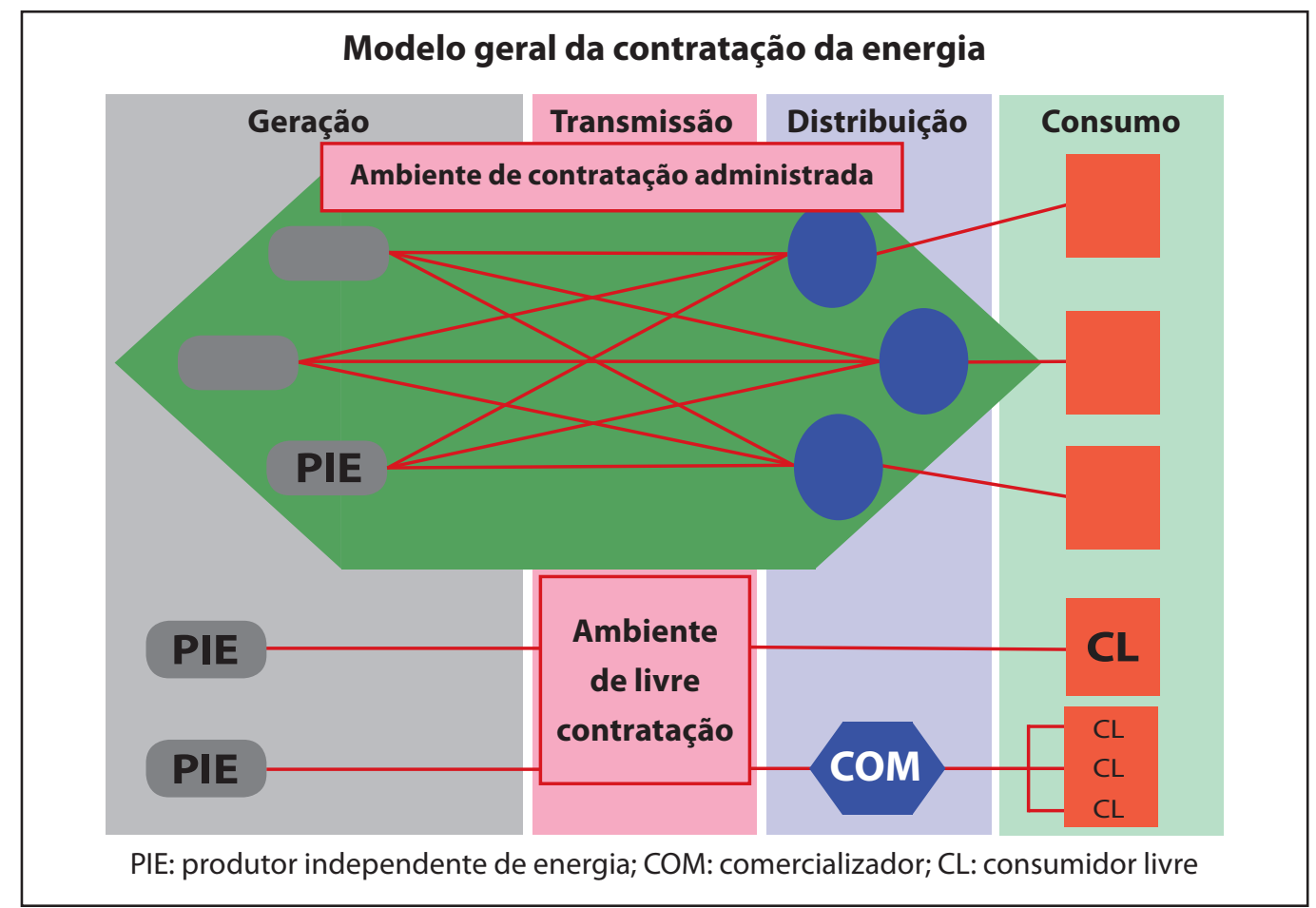

Fonte: Brasil/MME, 2003

Nesses casos, o Estado contratará diretamente os projetos adicionais de geração e transmissão que considera indispensáveis para atender à demanda. Assim, como regra, a ACE não contratará nem a compra nem a venda de energia diretamente; será uma mera repassadora de contratos.

Tolmasquim, 43 anos, provisoriamente também secretário de Política Energética do Ministério de Minas e Energia, é não apenas o coordenador mas o mentor dessa solução. Sua proposta surgiu depois que a ministra descartou outra fórmula, apresentada em 'Um Novo Modelo para o Setor Elétrico Brasileiro', texto assinado por Ildo Sauer, professor da Politécnica de São Paulo. Sauer, depois de Luiz Pinguelli Rosa, atual presidente da Eletrobras, foi talvez o principal articulador das propostas de política energética do Instituto da Cidadania, do então candidato Luiz Inácio Lula da Silva. Seu texto começou a ser preparado depois da vitória de Lula no segundo turno das eleições do ano passado; ficou pronto depois do carnaval; e foi debatido com a ministra no início de março. Como não foi aprovado, a Eletrobras, sob o comando de Pinguelli, criou o Genese Grupo de Estudo para Nova Estruturação do Setor Elétrico, com a participação de Sauer, para apresentar nova solução.

Posteriormente, o MME criou através da Portaria 040/2003 seu próprio grupo de trabalho, sob a coordenação de Tolmasquim. Agora, diz o secretário-geral, a proposta oficial está basicamente definida e em duas semanas será detalhada para apresentação formal e debate público.

Na proposta de Sauer, o órgão público encarregado da contratação de energia não seria apenas um repassador de contratos a serem feitos diretamente entre geradoras e distribuidoras. Ele contrataria as compras e as vendas. E, na intermediação entre a produção e o consumo, apropriaria, para o Estado e para os projetos de inclusão social do governo, a chamada renda hidráulica, decorrente do fato de as velhas geradoras hidrelétricas estatais produzirem energia a preços duas a três vezes menores que os do mercado global atual, 
definido pelos custos das geradoras termelétricas que prevalecem nos países desenvolvidos".

Sobre a proposta apresentada no início do ano, Bandeira (2003) opina:

"A figura $5^{1}$ reproduz ilustração do documento disponibilizado pelo MME, corroborando a conclusão de que, à luz da teoria relativa a modelos para a indústria de energia elétrica apresentada no presente documento, o MME não está propondo, de fato, uma alteração de modelo.

Realmente, para que ocorresse uma efetiva alteração de modelo do setor elétrico nacional, para um modelo com menos competição, um modelo do tipo 3 ou do tipo 2 (vide Capítulo I), extinguindo o ambiente de mercado e a figura do consumidor livre, haveria necessidade de rompimento de contratos vigentes, ou de oferecimento de vantagens adicionais aos agentes para que estes, voluntariamente, abrissem mão de direitos contratuais, resultantes, portanto, de ato jurídico perfeito. Ambas as hipóteses apresentam custos elevadíssimos para o país e resultariam num aumento do risco setorial, afastando investimentos privados do setor elétrico nacional, com implicações possíveis no risco país, e todas as consequências indesejáveis associadas. Não obstante estar sendo mantido o modelo de competição no varejo, a proposta divulgada pelo MME, como veremos adiante, introduz um agente de contratação de energia, o denominado Administrador dos Contratos de Energia Elétrica - ACEE, sem que se possa extinguir agentes existentes ou o ambiente de mercado, como visto. Em consequência, a introdução do agente proposto, no curto prazo, resultará no aumento da complexidade das regras, no aumento das incertezas para os investidores, e no aumento dos custos setoriais, refletindo-se inevitavelmente no aumento das tarifas. Os reflexos das alterações propostas para o setor, no médio prazo, serão abordados mais à frente no presente trabalho".

O modelo definitivo foi lançado em novembro de 2003, com a maioria das características que ainda apresenta, sobretudo quanto ao arranjo comer-

1 A "figura 5" à qual se refere o autor é uma reprodução da Figura $6 \mathrm{~b}$, extraída do documento original do MME. cial. Rosa et al. (2004) sintetizam a comparação entre as características do modelo de liberalização plena, da proposta oriunda das discussões do Instituto Cidadania e da proposta finalmente implementada pelo governo (Tabela 5).

\section{O SETOR ELÉTRICO}

\section{ATUAL - BREVE RETRATO}

O sistema elétrico brasileiro é um sistema hidrotérmico, com predominância de geração de base hidráulica. Trata-se de um sistema de grande porte, majoritariamente interligado (SIN - Sistema Interligado Nacional), com existência de sistemas isolados, dividido em quatro subsistemas: SE-CO, N, NE, S.

Além da geração hidrelétrica e termelétrica fóssil (gás natural, carvão, óleo combustível), renovável (biomassa residual e "virgem") e nuclear, incorpora geração eólica (crescente nos últimos anos), solar fotovoltaica (insignificante) e importação de energia. A geração hidrelétrica de grande porte, em especial as usinas mais antigas, é dotada de reservatórios de regularização (em período mais remoto, plurianual e, atualmente, intra-anual). Esses reservatórios acumulam água nos períodos úmidos e a liberam nos períodos secos.

A interligação do sistema, através de uma malha de transmissão de grande extensão e, consequentemente, das bacias hidrográficas nas quais se localiza a infraestrutura de geração, promove uma complementaridade entre os diversos regimes hidrológicos regionais. Permite, também, uma geração cerca de $25 \%$ superior à que seria obtida sem a interligação.

A operação do sistema é feita de forma centralizada, pelo Operador Nacional do Sistema (ONS), visando a garantir a segurança do suprimento ao menor custo possível (otimização e confiabilidade energética) e a estabilidade elétrica. Para o atendimento dessas premissas, é efetuado o planejamento da operação, cuja periodicidade pode ser diária, semanal, mensal, quadrimestral, anual e de mais longo prazo.

Como critério de garantia de suprimento, a estratégia de operação do SIN considera, atualmente, o teto para o risco de ocorrência de déficit de energia (risco de déficit) o não atendi- 


\section{TABELA 5}

\section{COMPARAÇÃO ENTRE O MODELO LIBERAL (FHC), O MODELO PROPOSTO PELO INSTITUTO CIDADANIA E O NOVO MODELO DO SETOR ELÉTRICO}

\begin{tabular}{|c|c|c|c|}
\hline Item & Modelo anterior & $\begin{array}{c}\text { Proposta do } \\
\text { Instituto Cidadania }\end{array}$ & Novo modelo \\
\hline Descontratação de energia & Sim & Suspender & Mantida \\
\hline Eletrobras no PND & Sim & Retirar & Retirada \\
\hline $\begin{array}{l}\text { Restrições de investimentos da } \\
\text { Eletrobras e de ser majoritária } \\
\text { em parcerias }\end{array}$ & Sim & Revogar & Não revogada \\
\hline Natureza da geração elétrica & Mercantil & Serviço público & $\begin{array}{l}\text { Serviço público } \\
\text { e mercantil }\end{array}$ \\
\hline Forma de exploração das usinas & $\begin{array}{c}\text { Produção } \\
\text { independente }\end{array}$ & Concessão & $\begin{array}{l}\text { Concessão com } \\
\text { muitos prod. ind. }\end{array}$ \\
\hline Geração e transmissão & Desverticalizar & Não desverticalizar & Não desverticaliza \\
\hline Mercado atacadista & $\begin{array}{c}\text { Indutor de } \\
\text { investimento }\end{array}$ & Extinguir & Substituído \\
\hline Garantia de suprimento & Mercado & Poder público & Poder público \\
\hline Produtores independentes & Maioria & Exceção & Grande número \\
\hline Planejamento & Indicativo & Determinativo & Determinativo \\
\hline Novas usinas & $\begin{array}{l}\text { Licitação onerosa } \\
\text { de hidrelétricas }\end{array}$ & $\begin{array}{l}\text { Licitar todas por } \\
\text { menor tarifa }\end{array}$ & $\begin{array}{l}\text { Licita todas por } \\
\text { menor tarifa }\end{array}$ \\
\hline Despacho de usinas & Oferta de menor preço & Menor custo & Menor preço \\
\hline Energias alternativas & Mercado & Política energética & Proinfa e mercado \\
\hline Térmicas a gás natural & Obedece a contratos & Complementar & Obedece a contratos \\
\hline Participação privada & Privatizações & Suspender & Suspensas \\
\hline Financiamento & $\begin{array}{l}\text { Atração de invest. } \\
\text { privados }\end{array}$ & $\begin{array}{l}\text { Recursos públicos } \\
\text { e privados }\end{array}$ & $\begin{array}{c}\text { Prioridade de invest. } \\
\text { privados }\end{array}$ \\
\hline Política energética & Dada pelo mercado. & $\begin{array}{c}\text { Definida pelo } \\
\text { governo }\end{array}$ & Indefinida \\
\hline Regulação & Aneel & Integrada & Aneel \\
\hline
\end{tabular}

Fonte: Rosa, 2004

mento de $5 \%$ do mercado. No período anterior à liberalização do setor, esse critério considerava inaceitável um risco superior a 5\% da ocorrência de qualquer déficit (Rosa et al., 2000). Um instrumento da gestão da operação é a curva de aversão ao risco, que mostra a evolução dos requisitos mínimos de armazenamento de energia (energia armazenável), em cada subsistema, para atendimento de toda a carga.

A gestão do setor elétrico brasileiro considera, para o planejamento da expansão, para o planejamento da operação e para a comercialização de energia, os custos marginais de curto (CMO - custo marginal de operação) e de lon- 
go prazo (CME - custo marginal de expansão). Os CMOs refletem o atendimento da demanda (carga incremental de $1 \mathrm{MW}$ ) sem incorporar a adição de novos empreendimentos, usando, para isso, a reserva do sistema, o aumento da importação ou a degradação da qualidade do abastecimento. Os CMEs refletem o atendimento da carga incremental considerando a incorporação de novos empreendimentos, além das demais alternativas. Por definição a confiabilidade ótima do sistema é atingida quando o CMO iguala o CME (EPE, 2011; Camargo, 1996). Essa premissa é adotada no planejamento setorial brasileiro, por recomendação do Banco Mundial, desde a década de 1980 (Santana, 1993; Camargo, 1996).

As características do sistema (hidrotérmico, interligado) tornam necessária a otimização do despacho - ordenamento no tempo e no espaço da entrada em operação de cada planta, para o atendimento da carga a cada momento -, a fim de obter o menor custo possível. São levados em conta, entre outros parâmetros, o custo da geração térmica, o "valor" da água e a demanda. A técnica utilizada para realizar a otimização é a programação dinâmica dual estocástica (PDDE), base do programa Newave, que, aplicada em conjunto com o programa Decomp, calcula o CMO.

A partir do CMO, é calculado o preço de liquidação de diferenças (PLD), introduzido na liberalização do setor, para balizar as transações spot no antigo Mercado Atacadista de Energia (MAE). O PLD foi mantido no atual modelo, valorando a energia nas operações de liquidação dos saldos no mercado de curto prazo, sob a coordenação da Câmara de Comercialização de Energia Elétrica (CCEE). Nisso o Brasil difere da maioria dos modelos internacionais, onde o preço é determinado por equilíbrio entre oferta e demanda, através de leilões de compra e venda (Queiroz, 2007). Desde então, o PLD vem sendo amplamente utilizado como sinalizador de valor e preço da energia no Brasil, sob as críticas de um grande número de especialistas do setor.

$\mathrm{O}$ arranjo comercial prevê um ambiente de contratação regulado (ACR) e um ambiente de contratação livre (ACL). No ambiente regulado, a contratação da energia se dá por meio de leilões (de várias modalidades), cujo critério para a seleção é a oferta do menor preço de venda da energia. No ACL, são feitas transações bilaterais entre compradores e vendedores que determinam entre si todas as condições do negócio. Trata-se de um modelo conhecido como multicontratação bilateral, proposto pelo Banco Mundial no início dos anos 2000 como forma de mitigar as diversas crises que atingiram mercados liberalizados em vários países (destaque para a crise da Califórnia e para a crise brasileira), reduzindo o grau de liberalização.

A regulação tarifária (distribuição) segue o modelo do preço-teto incentivado, que prevê reajustes anuais e revisões periódicas. No período entre as revisões, o concessionário pode se apropriar de todo o excedente que obtiver. Nas revisões, entretanto, é calculado o Fator X, que pode ser positivo ou negativo e, em tese, repartiria com a sociedade, no período seguinte, os ganhos de eficiência.

O atual modelo foi estabelecido pelo governo Lula, com premissas iniciais de garantir segurança do abastecimento, promover a universalização do acesso, a expansão das fontes renováveis e a modicidade tarifária. Entretanto, a manutenção das características básicas do modelo mercantil de FHC, o aumento da complexidade resultante da adoção do modelo de multicontratação bilateral, as inúmeras brechas inerentes ao arcabouço legal-institucional e vários equívocos de gestão resultaram, nos dez anos de sua duração, em uma das mais altas tarifas do mundo; persistente defasagem no planejamento e investimentos; precárias condições de manutenção e operação (sucessão de apagões e "apaguinhos") e na permanência de um ainda enorme contingente de "sem luz".

\section{CONSIDERAÇÕES FINAIS}

Desde que se tornou parte intrínseca do modo de vida urbano e industrial que hoje determina a existência da maior parte dos seres humanos do planeta, a energia elétrica adquiriu um caráter de essencialidade que dificilmente dela se dissociará. A despeito da forma encontrada para a prestação do serviço e dos custos 
associados, a não provisão de energia, sobretudo elétrica, pode determinar a inclusão social dos indivíduos e, em certos casos, sua própria sobrevivência. Na trajetória do setor elétrico brasileiro, várias reformas, revisões, "reestruturações" foram tentadas tendo, em vários momentos, tais experimentos se dado à custa do bem-estar da população.

Ao longo desse processo, o planejamento energético também teve seu caráter alterado, computando os mais sensacionais fracassos desde o período da liberalização do setor, nos anos 1990, até o presente. Desde o início do planejamento brasileiro, com o grupo Canambra, até finais, com a atuação plena da Eletrobras, de 1979, o uso do critério determinístico baseado nas séries históricas de vazões para expansão do sistema mostrou-se razoável embora gerasse incertezas, como o fato de não permitir a avaliação do risco. Em 1979, a programação dinâmica estocástica e a introdução da análise probabilística permitiram gerar mais cenários prováveis de afluência e a função do mínimo custo, inserindo também a operação com termelétricas. Porém, a avaliação do risco ficou limitada para hidraulicidades severas. Os sistemas Baltroc e Bacus ajudaram com a implementação desses novos critérios, porém ainda deixavam as trocas entre subsistemas incipientes. A introdução da programação dinâmica dual estocástica e o Newave, em 1998, deram mais eficiência na busca da otimização econômico-financeira, mais acorde com o mo- delo liberal mercantil que o setor passou a ter. Nas décadas de 1970 e 1980, a Eletrobras gerou uma série de planos que diversificaram a representação das fontes disponíveis para geração, inclusive as usinas nucleares e os potenciais hidráulicos da Bacia Amazônica foram incluídos, mas as conjunturas econômicas foram variando sua implementação.

O critério da segurança de abastecimento e, portanto, de risco também mudou, de acordo com os interesses dos atores e a configuração setorial do momento. Se antes do governo FHC tratava-se de prover socialmente o serviço, e o risco, assim como os benefícios, era compartilhado solidariamente entre os agentes, posteriormente cada um passou a buscar para si e em benefício próprio o menor prejuízo, ou a visar à arrecadação da maior parte possível do excedente.

A síntese desse quadro é a situação vivida atualmente pelo setor elétrico brasileiro que, detentor de uma enorme capacidade e um acúmulo de conhecimento na área de planejamento de expansão da oferta e de operação de um dos sistemas mais complexos e sinérgicos do mundo, como se tentou descrever, vê-se à beira de um colapso técnico e econômico como poucos países - se é que algum já passou por isso - já viveram. A pergunta que permanece sobre qual será o melhor método e qual a melhor orientação para planejar o setor elétrico brasileiro, mais uma vez, está sem resposta - o futuro, em breve, dirá. 


\section{BIBLIOGRAFIA}

AMARAL, L. F. M. Modelos Lineares e Não Lineares na Modelagem do Preço Spot de Energia Elétrica do Brasil. Dissertação de mestrado. Rio de Janeiro, Programa de Pós-Graduação em Engenharia Elétrica do Departamento de Engenharia Elétrica da PUC-Rio, 2003.

ANEEL - Agência Nacional de Energia Elétrica. Superintendência de Planejamento da Gestão - SPG. Prestação de Contas Ordinária Anual. Relatório de Gestão do Exercício de 2013. Brasília, Aneel, 2014.

BANDEIRA, F. P. M. “Análise das Alterações Propostas para o Modelo do Setor Elétrico Brasileiro", in Consultoria Legislativa - Estudo. Brasília, Câmara dos Deputados, 2003. BRASIL. MME - Ministério de Minas e Energia. Secretaria de Energia. Reestruturação do Setor Elétrico Brasileiro: Encaminhamentos e Resultados. Brasília, MME/SEN, 1998. Proposta de Modelo Institucional para o Setor Elétrico. Brasília, 2003.

CAMARGO, C. C. B. Gerenciamento pelo Lado da Demanda: Metodologia para Identificação do Potencial de Conservação de Energia Elétrica de Consumidores Residenciais. Tese de doutorado. Florianópolis, Programa de Pós-graduação em Engenharia de Produção da Universidade Federal de Santa Catarina, 1996.

D'ARAÚJO, R. P. O Setor Elétrico Brasileiro - uma Aventura Mercantil. Brasília, Confea, 2009.

EPE - Empresa de Pesquisa Energética. Aspectos Fundamentais do Planejamento Energético. Rio de Janeiro, EPE, 2005.

"Custo Marginal de Expansão: Metodologia de Cálculo 2011", in Nota Técnica EPE-DEE-RE-091/2011-rO. Rio de Janeiro, EPE, 2011.

HOLLAUER, G. "Pesquisa e Desenvolvimento de Fontes Renováveis de Energia", in Conferência Brasileira de Energia - Sustentabilidade Energética no Século XXI, 2011. Brasília. Disponível em: http://www2.camara.gov.br/atividade-legislativa/comissoes/ comissoes-permanentes/cmads/notastaq/congresso/conferencia-brasileira-de-energia6-e-7-12-2011/gilberto-hollauer_mme/view. Acesso em: 13/11/2014.

IANNONE, R. A. Evolução do Setor Elétrico Paulista. Tese de doutorado. São Paulo, Faculdade de Filosofia Letras e Ciências Humanas, Departamento de História da USP, 2006.

KLIGERMANN, Alberto Sergio. Um Sistema de Apoio à Decisão Bicritério para o Planejamento da Operação Energética. Tese de doutorado. Niterói, Universidade Federal Fluminense, 2009.

LOVEI, L. "Single Buyer Model: a Dangerous Path Toward Competitive Electricity Markets", in Public Policy for the Private Sector. Note n. 225. Washington, DC, World Bank Group, Private Sector and Infrastructure Network, dez. 2000.

MACHADO, A. C. F. "A Evolução do Mercado Livre de Energia", in Enase - Encontro Nacional dos Agentes do Setor Elétrico, IV. São Paulo, 13 de setembro de 2007.

MELLO, M. F. "Os Impasses da Privatização do Setor Elétrico", in Texto para Discussão № 365. Rio de Janeiro, Departamento de Economia da PUC-RJ, 1996.

MERCEDES, S. S. P. Análise Comparativa dos Serviços Públicos de Eletricidade e Saneamento Básico no Brasil: Ajustes Liberais e Desenvolvimento. Tese de doutorado. São Paulo, Programa Interunidades de Pós-graduação em Energia da USP, 2002.

"Marcos Constitutivos do Setor Elétrico Brasileiro", in Gildo Magalhães (org.). História e Energia: Memória, Informação e Sociedade. 1 ed. São Paulo, Alameda Casa Editorial, 2012a, v. 1, pp. 105-24. 
Economia da Geração Termoelétrica: Curso de Especialização Lato Sensu, Gestão e Supervisão de Termelétricas. São Paulo, IEE-USP, 2012b.

OLIVEIRA, A et al. "Setor Elétrico", in F. Rezende; T. B. Paula (coords.). Infraestrutura: Perspectivas de Reorganização: Setor Elétrico. Brasília, Ipea, 1997.

PALOCCI FILHO, A.; DANIEL, C. Programa de Governo 2002 Coligação Lula Presidente. São Paulo, Comitê Lula Presidente, 2002.

PEREIRA, R. R. O Debate sobre um Novo Modelo para o Setor Elétrico: o Plano Tolmasquim. Rio de Janeiro, Ponto de Vista, 2/5/2003. Disponível em: http://www.provedor.nuca.ie.ufrj. br/eletrobras/artigos/pereira1.htm. Acesso em: 18/5/2015.

QUEIROZ, A. R. Simulação de Custos Marginais em Mercado de Energia Elétrica Utilizando Redes Neurais. Dissertação de mestrado. Itajubá, Programa de Pós-Graduação em Engenharia Elétrica da Universidade Federal de Itajubá, 2007.

ROSA, L. P. et al. "Diretrizes e Linhas de Ação para o Setor Elétrico Brasileiro - Instituto de Cidadania", in Congresso Brasileiro de Energia, X, A Universalização do Acesso à Energia. Rio de Janeiro, 2004. Disponível em: http://www.ppe.ufrj.br/xcbe/apresent/M1_Luiz_ Pinguelli.pps. Acesso em: 18/5/2015.

ROSA, L. P.; TOLMASQUIM, M. T.; D'ARAUJO, R. O Brasil e o Risco de Déficit de Energia. Rio de Janeiro, COPPE/UFRJ, 2000. Disponível em: http://www.provedor.nuca.ie.ufrj.br/ espanol/estudos/pinguele2.doc. Acesso em: 5/4/2013.

SANTANA, E. A. "Questões Fundamentais para o Estudo da Economia de Escala do Setor Elétrico Brasileiro", in Textos de Economia, 4(1), 53-62, 1993.

SAUER, I. L. "Um Novo Modelo para o Setor Elétrico Brasileiro", in I. L. Sauer et al. (orgs.). A Reconstrução do Setor Elétrico Brasileiro. São Paulo, Paz e Terra, 2003.

TERRY, L. A. et al. "Coordinating the Energy Generation of the Brazilian National Hydrothermal Electric Generating System", in Interfaces, v. 16, 1: January-February, 1986, pp. 16-38.

ZAMBELLI, M. S. Planejamento da Operação Energética Via Curvas-Guias de Armazenamento. Campinas. Dissertação de mestrado. Campinas, Unicamp, 2006. 